\title{
Mulheres em Espera pela Adoção: Sentimentos Apresentados nas Diferentes Etapas Desse Processo
}

\author{
Monique Souza Schwochow ${ }^{1}$ \\ Giana Bitencourt Frizzo ${ }^{1}$ \\ ${ }^{1}$ Universidade Federal do Rio Grande do Sul, RS, Brasil. \\ ${ }^{1}$ Universidade Federal do Rio Grande do Sul, RS, Brasil.
}

Resumo: Este estudo tem o objetivo de compreender quais os sentimentos relatados por mulheres na espera pela adoção em dois diferentes momentos: na espera durante o processo de habilitação à adoção e na fila do Sistema Nacional de Adoção e Acolhimento (SNA). Esses anseios têm sido descritos na literatura de forma pouco específica no que diz respeito às etapas do processo de adoção, ainda que mulheres em espera pela adoção experimentem emoções singulares devido à indeterminação temporal em sua transição para a maternidade. Participaram deste estudo quatro mulheres, com idade entre 38 e 44 anos, ativas e em espera no SNA há menos de um ano. Por meio da análise qualitativa dos dados, identificou-se que as diferentes fases do processo de adoção mobilizavam diferentes sentimentos. Durante a habilitação à adoção, sentimentos como apreensão, frustração, dor e morosidade foram descritos. Já na espera no SNA, os sentimentos puderam ser alocados em duas categorias: esperança e desesperança. Os resultados desta pesquisa contribuem para a literatura sobre o processo de espera na adoção por meio da elucidação dos sentimentos envolvidos nas duas distintas etapas.

Palavras-chave: Maternidade, Adoção, Futuras Mães por Adoção, Habilitação à Adoção, Cadastro Nacional de Adoção.

\section{Women Waiting to Adopt a Child: Feelings Experienced in the Different Stages of the Process}

\begin{abstract}
In their transition to motherhood, women waiting to adopt a child experience a series of emotions of temporal indetermination. However, the literature addressing the longings inherent to each step of the adoption process is still rather scarce. Thus, this study aimed to understand the feelings experienced by women waiting to adopt in two different moments: the adoption application process and the National Adoption Registry (NAR) queue. This study was conducted with four women, aged between 38 and 44 years, who were active and waiting for less than one year in the NAR. A qualitative analysis verified that different feelings were evoked in each phase of the process. Whereas the adoption application process evoked feelings of apprehension, frustration, pain, and slowness, the process referring to the NAR queue arouse feelings that could be allocated into two different categories: hope and hopelessness. These findings contribute to the existing literature on the adoption waiting process, especially by clarifying the feelings evoked in its different stages.
\end{abstract}

Keywords: Maternity, Adoption, Future Adoptive Mothers, Adoption Application, National Adoption Registry. 


\title{
Mujeres en Espera por la Adopción: Sentimientos en las Diferentes Etapas del Proceso
}

\begin{abstract}
Resumen: Este estudio tuvo como objetivo comprender los sentimientos relatados por las mujeres aspirantes a la adopción en dos diferentes momentos: en la espera para el proceso de habilitación a la adopción y en la espera en el Registro Nacional con fines de Adopción (SNA, por sus siglas en portugués). En la literatura se encuentran pocos estudios que abordan las etapas del proceso de adopción, frente a las emociones que las mujeres aspirantes a la adopción experimentan debido a la indeterminación temporal en su transición para la maternidad. En este estudio participaron cuatro mujeres, con edades entre 38 y 44 años, activas y en espera en el SNA hace menos de un año. El análisis cualitativo de los datos apuntó que las diferentes etapas del proceso de adopción movilizaban diferentes sentimientos. Durante la habilitación a la adopción, se relataban sentimientos como la aprehensión, la frustración, el dolor y la morosidad. Ya en espera en el SNA, los sentimientos pudieron ser asignados en dos categorías: esperanza y desesperanza. Los resultados de esta investigación contribuyen a la literatura sobre el proceso de espera por la adopción por medio de la elucidación de sentimientos involucrados en sus etapas.
\end{abstract}

Palabras clave: Maternidad, Adopción, Futuras Madres por Adopción, Habilitación a la Adopción, Registro Nacional con Fines de Adopción.

\section{Introdução}

O empenho de filósofos e escritores em construir uma representação acerca do conceito tempo é incansável e, por meio de ensaios, poemas e poesias, eles tentam encontrar o sentido do tempo ao longo do curso de vida. Quando o tempo se refere à espera por algo que se anseia, sua compreensão se torna ainda mais complexa. As reflexões deste estudo contemplarão um contexto e seu tempo de espera específico: o da maternidade por adoção.

Estudos acerca do processo de adoção frequentemente carecem de informações relacionadas ao tempo. Mães por adoção podem sofrer com a ausência de marcadores temporais e dos ritos na passagem para a entrada na parentalidade. Dar significado ao início, à duração e ao fim da espera pela adoção é uma forma de validar o progresso dessas mulheres em relação ao processo de se tornarem mães. Quando uma linha do tempo é construída pelas futuras mães adotivas, isso pode ajudá-las a enfrentar as adversidades do processo não biológico de maternidade (Sandelowski, Harris, \& Holditch-Davis, 1991).

Naturalmente, esse tempo de espera é carregado de emoções. A literatura científica tem, ainda que de forma escassa, tentado entender os sentimentos envolvidos na espera pela adoção. No entanto, parece não haver uma organização clara dos sentimentos relatados em cada etapa dessa espera. Fala-se no período de pré-adoção (Fontenot, 2007) como aquele que se estende desde a decisão pela adoção até a chegada da criança, porém pouco se sabe sobre as especificidades de cada fase dessa espera. Alguns estudos discorrem sobre os sentimentos relatados no processo de habilitação à adoção e sobre a espera das famílias habilitadas de forma conjunta e, por vezes, pouco delimitada acerca do período ao qual estão se referindo (Costa \& Kemmelmeier, 2013; Daniluk \& Hurtig-Mitchell, 2003; Fontenot, 2007; Huber \& Siqueira, 2010, Mahl \& Jaeger, 2011; Schettini, Amazonas, \& Dias, 2006).

Para tentar elucidar essas duas diferentes fases de espera, é necessário primeiro entender como acontece a candidatura à adoção no Brasil. No país, maiores de 18 anos podem tentar adotar uma criança ou adolescente, independentemente de seu estado civil, respeitando a diferença mínima de 16 anos de idade entre o adotante e o adotado, entre outros critérios (Lei n. 12.010, 2009). De acordo com a legislação brasileira, o pretendente à adoção deve ser submetido a um processo de preparação psicossocial jurídica. Uma equipe interprofissional - que conta com ao 
menos um assistente social e um psicólogo - é responsável por acompanhar os candidatos nesse processo e por fornecer, por meio de uma avaliação psicossocial, os dados necessários para a tomada de decisão judicial a respeito da habilitação à adoção (Sebastiany, 2011). Ainda, a promoção de encontros em grupos de candidatos parece ser um movimento recente das equipes interprofissionais de técnicos judiciários, a fim de otimizar o tempo de espera do processo de habilitação à adoção. Dados do Sistema Nacional de Adoção e Acolhimento (SNA) mostram que, atualmente, 32.692 pretendentes disponíveis estão habilitados no país aguardando a chegada de seus filhos por adoção, dentre os quais 6.535esperam por crianças de $0 \mathrm{a}$ 2 anos de idade (Conselho Nacional de Justiça, 2021).

No processo de habilitação, os pretendentes à adoção passam a ter vivências e sentimentos próprios desse momento de transição para a parentalidade. Paiva (2004) e Brodzinsky e Pinderhughes (2002) mencionaram a sensação dos indivíduos de inserção em um processo avaliativo. Complementando, Paiva (2004) sugeriu que, ao entender esse momento como uma avaliação, os candidatos podem apresentar perdas em sua espontaneidade, visto que podem tender a um discurso mais normativo, pautado em convenções sociais ou elementos que, de acordo com suas crenças, podem ser valorizados pelos técnicos judiciários. A sensação de estarem sendo julgados por aqueles que avaliam é relatada pelos pretendentes (Daniluk \& Hurtig-Mitchell, 2003; Silva, 2015).

Dance e Farmer (2014) descreveram o período de habilitação como uma fase de preparação e avaliação dos candidatos à adoção. Nesse mesmo estudo, pouco mais da metade dos 27 participantes ingleses classificou a experiência de habilitação como positiva. Porém, descreveram-na como intensa, difícil e emocional, o que parece soar contraditório. Aquelas que avaliaram a experiência como nem positiva e nem negativa e aqueles que a classificaram como neutra ou negativa acabaram se referindo ao processo como frustrante e perturbador. Cabe ressaltar que, em outras regiões do mundo, como na Inglaterra e nos Estados Unidos, famílias que buscam a adoção podem fazê-la por meio de agências especializadas, diferentemente do Brasil, onde o processo é de jurisdição pública.

O sentimento de frustração ao longo do processo de habilitação à adoção, especialmente no início e no final do processo, pode ser frequente (Geen, Malm, \& Katz, 2004). Uma observação particular do estudo de
Dance e Farmer (2014) foi que os participantes que classificaram a experiência de avaliação como difícil sofreram atrasos em seus processos. Segundo os autores, os atrasos aconteceram tanto na entrega de exames e documentações por parte dos candidatos quanto na marcação dos encontros entre o serviço e a família, visto que alguns avaliadores os adiaram pelas mais diversas razões. Dificuldades de progresso na verificação de informações também tornaram esse processo vulnerável aos atrasos. Esses achados corroboram a sensação de perda de controle durante a habilitação à adoção (Sandelowski et al., 1991).

Com frequência, os futuros pais adotivos queixam-se da burocracia e da lentidão que experimentaram durante a habilitação à adoção (Costa \& Kemmelmeier, 2013; Dance \& Farmer, 2014; Gondim et al., 2008; Mahl \& Jaeger, 2011) e as famílias manifestam o desgaste causado pela duração do processo (Huber \& Siqueira, 2010). Costa e Kemmelmeier (2013) citaram ansiedade, paciência e burocracia como emoções sentidas por futuros pais adotivos. A ansiedade referia-se ao sentimento de expectativa constante na vida dos pais que lidavam com a indeterminação temporal do processo de adoção; a paciência dizia respeito à conformidade com essa espera e até mesmo um medo dos pais de que o processo de adoção não fosse resolvido pela justiça; e, por fim, a burocracia falava dos sentimentos de indignação e de revolta dos pais adotivos pelo descaso da justiça com as crianças abrigadas e seus processos. Para alguns candidatos à adoção, a burocracia pode gerar turbulências psíquicas e levar à desmotivação com o processo. Segundo os autores, a burocracia pode ser entendida, ainda, como uma falta de incentivo aos novos interessados na adoção.

Ainda sobre as emoções relatadas nesta espera, o estudo realizado pelas canadenses Daniluk e Hurtig-Mitchell (2003) constatou que o processo de habilitação à adoção era classificado como árduo e desafiador pelos participantes. Os 39 casais entrevistados nessa pesquisa indicaram que se sentiram impotentes, com raiva e frustrados. Porém, reconheceram também sentimentos de solidariedade entre o casal e a sensação de que ambos tinham um propósito compartilhado. Nesse mesmo estudo os participantes referiram sentirem-se "sem saída", visto que, apesar de suas insatisfações com o processo de habilitação, deveriam suportá-lo caso desejassem a parentalidade por adoção. 
Além disso, os entrevistados desse estudo demonstraram desconforto em relação às decisões quanto ao perfil da criança que desejariam adotar, referindo que essas são escolhas que outros pais raramente precisam enfrentar (Daniluk \& Hurtig-Mitchell, 2003). Corroborando esse achado, Santos (1987) defende que pais por adoção precisam atingir um nível mais elevado na decisão de ter filho do que muitos pais biológicos, isso porque, para adotarem, os candidatos precisam levar adiante uma série de providências e escolhas iniciais, que não necessariamente são refletidas e feitas em uma gestação biológica.

Assim como a decisão pela adoção pode ocorrer de imediato ou levar longos anos (Gondim et al., 2008), a espera pela criança também pode variar na questão de tempo. Com o fim do processo de habilitação e o resultado positivo nele, os futuros pais por adoção entram no que Sandelowski et al. (1991) chamam de "período de espera oficial". Os autores salientam que os pais costumam sentir alívio ao conseguirem a aprovação para habilitação à adoção, pois esta é vista como um sucesso em seus esforços para alcançar a parentalidade. Segundo os autores, especialmente para os casais inférteis, a aprovação na habilitação à adoção promove a sensação de avanço, ou seja, de progresso em direção ao tornarem-se pais. Sandelowski et al. (1991) acreditam que os futuros pais por adoção se sentem, de alguma forma, especiais, visto que a adoção não é para todos - fazendo referência àqueles que não conseguem a aprovação.

Inicia-se então um novo período de espera que tem um tempo de duração indeterminado, no qual os pais estão propensos ao estresse de saber que a qualquer momento podem receber uma ligação avisando que deverão receber seu filho dentro de dois a três dias (Rampage et al., 2016). Apesar de todas as dificuldades e medos que esse processo abarca, Souza e Casanova (2012) destacam que a espera pela adoção deve ser compreendida como um momento de amadurecimento e convicção do desejo de ter um filho.

Estar na fila do SNA parece movimentar sentimentos específicos dessa condição de espera. Alguns futuros pais por adoção podem sentir dificuldades em manterem-se animados com a possibilidade de chegada do filho com o passar dos anos (Daniluk \& HurtigMitchell, 2003; Sandelowski et al., 1991). A espera pela adoção pode ser definida por aqueles que a vivenciam como extensa, difícil, ansiogênica e desgastante (Dance \& Farmer, 2014; Huber \& Siqueira, 2010;
Mahl \& Jaeger, 2011; Schettini et al., 2006), ou, ainda, como uma tortura (Sandelowski et al., 1991). A longa espera pode levar casais a construírem uma perspectiva cada vez mais negativa em relação à espera pela adoção (Sandelowski et al., 1991). Para esses futuros pais, pode ser complicado suportar o fardo do tempo em uma espera sem roteiro, e alguns se sentem até mesmo à deriva no tempo (Sandelowski et al., 1991), esquecidos ao longo dessa espera, podendo reportar a impressão de que nada está acontecendo (Reppold, Chaves, Nabinger, \& Hutz, 2005).

A sensação de otimismo vivenciada com as perspectivas de adoção pode dar lugar à ansiedade e à frustração de saber que um longo processo de espera se inicia. A indeterminação do tempo pode levar ao seu preenchimento com angústias que tendem a se intensificar com o passar dos anos (Mahl \& Jaeger, 2011). Brodzinsky e Pinderhughes (2002) constataram que a incerteza do período de espera geralmente leva ao sofrimento, à confusão e à sensação de desamparo. Por sua vez, o estudo de Fontenot (2007) encontrou a descrição dos seguintes sentimentos a respeito da espera pela adoção: incerteza, rejeição, competição, isolamento, julgamento, apreensão, desamparo, tomada de riscos e medo, mas também esperança, alegria e amor. Percebe-se, portanto, que esse período pode despertar emoções complexas e, por vezes, contraditórias em relação à transição para a parentalidade. Talvez por essa razão alguns estudos aconselhem a busca por apoio psicológico nessa fase para os futuros pais (Gondim et al., 2008; Mahl \& Jaeger, 2011; Schettini et al., 2006).

Durante a espera, os futuros pais podem experimentar uma tensão carregada de expectativas, preocupações, mas também de esperança. Os medos e angústias dos pais em espera devem ser considerados (Schettini et al., 2006). Huber e Siqueira (2010) atentam para a possibilidade de sofrimento durante a espera na fila para adoção. De acordo com os autores, durante o tempo de espera pela chegada do filho podem aumentar as fantasias referentes à adoção e à demora, levando os futuros pais a realizarem inúmeros questionamentos a respeito dessa configuração de transição para a parentalidade. Essa vivência deve ser bem elaborada, pois a combinação entre a idealização do futuro filho e os sentimentos ambivalentes e ansiogênicos pode comprometer a futura relação entre pais e filhos adotivos. O lugar reservado para a criança no imaginário dos pais pode ficar abalado (Mahl \& Jaeger, 2011). 
Ainda, a literatura aponta que a infertilidade é o motivo de maior incidência na busca pela adoção (Rampage et al., 2016; Schettini Filho, 1998). Portanto, pode-se sugerir que, nesses casos, a perda éum tema presente desde o início da adoção (Rampage et al., 2016). Alguns autores sugerem que o período de espera pela adoção pode compreender também um período de elaboração da perda do filho biológico (Mahl, Jaeger, Patias, \& Dias, 2012; Schettini et al., 2006). Quando se trata da infertilidade nas mulheres, é preciso ressaltar que o fato de não conseguir engravidar pode ser interpretado como uma distorção em sua condição enquanto mulher. Para muitas, a infertilidade tem relação direta com a feminilidade. O sentimento de culpa - antes mencionado - pode surgir, especialmente por meio da ideia de que são responsáveis por uma extinção genealógica e de que não podem corresponder às expectativas de seus parceiros de constituir uma família com filhos (Schettini Filho, 1998). Em alguns casos, o tempo de espera pode auxiliar a curar feridas causadas pela impossibilidade de gestar biologicamente.

É comum os pais em espera pela adoção nomearem seu processo temporal como uma gestação emocional (Schettini et al., 2006), gestação adotiva (Huber \& Siqueira, 2010), ou, ainda, gestação sem barriga (Mahl \& Jaeger, 2011). De fato, é importante que os futuros pais gestem um novo papel, como sugerem Cecílio e Scorsolini-Comin (2016). Os autores acreditam que nesse importante momento do ciclo vital, o de tornarem-se pais, é preciso dedicar-se aos ajustes e adaptações que as novas tarefas e necessidades da parentalidade irão exigir.

Por fim, Sandelowski et al. (1991) observaram em seu estudo que os casais buscam um "horizonte temporal”, assim referido pelos autores, para darem significado a sua espera. Identificar o tempo de espera e, portanto, sua duração, auxilia na organização e regulação dos pensamentos e das atividades nessa passagem do tempo no tornarem-se pais. É importante que, apesar dos momentos críticos e de sofrimento para aqueles que esperam, os futuros pais possam se permitir esperar com alegria seu futuro filho. Além disso, os futuros pais devem tentar manter o equilíbrio de suas vidas durante a espera, não só buscando por uma família, mas também por outros movimentos que lhes tragam prazer (Daniluk \& Hurtig-Mitchell, 2003).

A discussão proposta salienta a importância do tema, especialmente sua necessidade de aprofundamento. Diante da evidente relevância da ação temporal na espera pela adoção (Costa \& Kemmelmeier, 2013; Dance \& Farmer, 2014; Huber \& Siqueira, 2010; Sandelowski et al., 1991; Schettini et al., 2006), torna-se imprescindível elucidar os sentimentos dos candidatos à adoção nas distintas fases desse processo. Isso porque as informações até então fornecidas pela literatura mostram-se pouco claras quanto ao período de espera ao qual se referem. Tendo isso em vista, este estudo tem como objetivo compreender quais os sentimentos relatados por mulheres na espera pela adoção em dois diferentes momentos: no processo de habilitação à adoção e na fila do SNA.

\section{Método}

\section{Participantes}

Participaram deste estudo quatro mulheres que estavam, na ocasião da entrevista, aguardando há menos de um ano na fila de espera para adoção no SNA em comarcas da região metropolitana de Porto Alegre. Elas tinham entre 38 e 44 anos, o perfil da criança desejada para três das participantes era de 0 a 2 anos e, para uma entrevistada, de 0 a 6 meses de idade. Entre essas quatro futuras mães por adoção, três referiram ter ensino superior completo e uma indicou ter pós-graduação. Sobre o estado civil, duas das quatro participantes eram solteiras, uma das quais estava em um relacionamento, e as outras duas eram casadas. Todas as participantes definiam-se como heterossexuais, estavam em um processo de adoção de acordo com as leis brasileiras e desejavam uma adoção nacional.

As mulheres que integram este estudo eram participantes do projeto "Transição para a parentalidade adotiva: pesquisa e intervenção” (Frizzo et al., 2016). As participantes do projeto deveriam ter mais de 18 anos de idade e poderiam ter nível socioeconômico variado, bem como diferentes configurações familiares.

Para este estudo, foram selecionados os casos de mulheres heterossexuais, solteiras ou casadas, à espera de bebês de até dois anos de idade. Esses critérios foram utilizados para tentar compor um grupo mais homogêneo (Flick, 2009) a fim de permitir a comparação dos sujeitos entre si. Particularmente, foi meta deste estudo dar voz às mulheres pelo reconhecimento social e científico delas como principais cuidadoras dos filhos. Ainda, escolheram-se os casos de futuras mães por adoção que esperavam há menos de um ano no 
SNA por bebês de 0 a 2 anos de idade, pois buscava-se compreender um aspecto temporal próximo do gestar psiquicamente dito pela gestação biológica (Cecílio \& Scorsolini-Comin, 2016; Huber \& Siqueira, 2010; Mahl \& Jaeger, 2011; Schettini et al., 2006).

\section{Delineamento}

Foi utilizado um delineamento de estudo de caso coletivo (Stake, 1994) a fim de compreender e comparar as entrevistas das futuras mães por adoção, investigando assim seus sentimentos durante a espera no processo de habilitação à adoção e espera na fila no SNA.

\section{Procedimentos}

O projeto de pesquisa do qual este estudo faz parte foi aprovado pelo Comitê de Ética da Universidade Federal do Rio Grande do Sul (UFRGS) e atende à resolução 510 de 2016 do Conselho Nacional de Saúde (CAEE n. 58061816.4.1001.5334).

Algumas participantes foram convidadas a contribuir com este estudo por meio das mídias sociais e entraram em contato de forma voluntária com os pesquisadores por intermédio dos meios de contato disponibilizados. Ainda, mediante autorização do juiz do $2^{\circ}$ Juizado da Infância e da Juventude de Porto Alegre (RS), técnicas judiciárias fizeram contato com as mulheres com o perfil desejado de participantes para este estudo a fim de convidá-las a colaborar com os estudos sobre adoção. Este estudo segue a definição de amostra por critério, como sugere Patton (2002). Após a resposta afirmativa das participantes, foi estabelecido o contato entre elas e os pesquisadores. Logo após o contato inicial, essas mulheres foram convidadas a comparecer Instituto de Psicologia (UFRGS) ou então forneceram um endereço para um encontro, no qual assinaram um Termo de Consentimento Livre e Esclarecido (TCLE). Posteriormente elas responderam ao questionário sobre a adoção (Núcleo de Pesquisa e Intervenção em Família com Bebês e Crianças [Nufabe], 2016) e à entrevista sobre as expectativas e os sentimentos na adoção (Nufabe, 2016).

\section{Instrumentos}

Questionário sobre a adoção (Nufabe, 2016): instrumento para fins de levantamento sobre dados sociodemográficos dos participantes e informações sobre o processo de habilitação para adoção.
Entrevista sobre as expectativas e os sentimentos na adoção (Nufabe, 2016): adaptada de Krahl (2003), consiste em uma entrevista semiestruturada cujo objetivo é abordar temas relativos à expectativa e aos sentimentos dos participantes em relação à adoção. Aborda também temas relacionados à experiência de espera pela chegada do filho, às percepções sobre como tem sido essa experiência para o cônjuge, ao envolvimento da família extensa e às características da criança pretendida.

\section{Análise dos dados}

As informações coletadas por meio do questionário sobre a adoção (Nufabe, 2016) foram utilizadas apenas para caracterização das participantes do projeto. Os dados da entrevista sobre as expectativas e os sentimentos na adoção (Nufabe, 2016) foram analisados por meio de análise temática (Braun \& Clarke, 2006). A análise foi realizada com o auxílio do software NVivo, versão 11, para a organização das informações coletadas. Esse software permite o tratamento de dados por meio de sua codificação, viabilizando o estabelecimento de uma estrutura de ideias temáticas sobre as fontes de dados. Dois principais temas foram definidos previamente: sentimentos na espera do processo de habilitação à adoção e sentimentos na espera no SNA. No primeiro tema surgiram quatro subtemas que indicavam os sentimentos presentes nessa etapa: apreensão, frustração, dor e morosidade. Por sua vez, no segundo tema foi possível identificar dois subtemas que apontavam para sentimentos expressos nessa outra etapa de espera pela adoção: esperança e desesperança.

\section{Resultados}

Para tornar claro o contexto de espera das participantes deste estudo, foi realizada uma breve descrição sociodemográfica delas (Tabela 1). Entende-se que a caracterização das mulheres entrevistadas é relevante para a compreensão de suas esperas, tanto no processo de habilitação à adoção quanto na espera no SNA. Ressalta-se que os dados referentes à espera na habilitação à adoção foram coletados de forma retrospectiva, enquanto as informações sobre a espera no SNA foram fornecidas durante a própria etapa. Posteriormente à Tabela 1, os dados encontrados foram apresentados de acordo com as duas diferentes fases de espera na adoção investigadas neste estudo. 
Tabela 1

Descrição sociodemográfica das participantes.

\begin{tabular}{|c|c|c|c|c|c|c|}
\hline Entrevistada & Idade & Estado civil & Escolaridade & $\begin{array}{c}\text { Histórico } \\
\text { clínico de } \\
\text { infertilidade }\end{array}$ & $\begin{array}{l}\text { Tempo aproximado de } \\
\text { espera do processo de } \\
\text { habilitação à adoção }\end{array}$ & $\begin{array}{c}\text { Tempo } \\
\text { aproximado de } \\
\text { espera no SNA }\end{array}$ \\
\hline $\mathrm{P} 1^{\mathrm{b}}$ & 43 anos & $\begin{array}{c}\text { Solteira } \\
\text { (namorando) }\end{array}$ & $\begin{array}{c}\text { Pós- } \\
\text { graduação }\end{array}$ & Sim & 3 meses e meio & 8 meses \\
\hline $\mathrm{P} 2$ & 38 anos & Casada & $\begin{array}{l}\text { Superior } \\
\text { completo }\end{array}$ & Sim & 9 meses e meio & 3 meses \\
\hline P3 & 44 anos & Solteira & $\begin{array}{l}\text { Superior } \\
\text { completo }\end{array}$ & Sim & 11 meses & 8 meses \\
\hline $\mathrm{P} 4$ & 42 anos & Casada & $\begin{array}{l}\text { Superior } \\
\text { completo }\end{array}$ & Sim & 1 ano e 10 meses & 4 meses \\
\hline
\end{tabular}

a Com base na data da entrevista.

b "P" refere-se à participante.

\section{Sentimentos na espera do processo de habilitação à adoção}

Nos discursos das quatro participantes destacaram-se as exposições de sentimentos de apreensão, frustração, dor e morosidade quanto ao processo de habilitação à adoção. As entrevistadas se sentiram, de forma geral, mobilizadas emocionalmente pelos encontros com os técnicos judiciários. Seus relatos evidenciaram a comoção de sentimentos relacionados ao caráter analítico do processo e ao fato de se darem conta, de uma forma mais realista, dos trâmites do processo de adoção.

Ilustrando o sentimento de apreensão, a Participante 1 disse:

Foi bom, mas ao mesmo tempo apreensivo, né? Porque eu estava sendo, de certa forma, avaliada e analisada, e isso não é muito bom, né? Mas foi muito. . . Eu sabia que era uma causa nobre, por um bom motivo, então eu tentava relaxar como eu podia. Mas sempre aquele questionamento: "Será que fui bem? Será que vai dar certo?" . . . Então, totalmente um sentimento, uma tremura, uma angústia total naquele momento $(\mathrm{P} 1)$.

A participante falou ainda sobre a falta de resposta em relação a sua habilitação, dizendo que não teve nenhum retorno e, portanto, decidiu ligar para saber sobre seu processo. Somente após seu movimento de contato ficou sabendo que já estava habilitada:

Na segunda eu liguei e daí um rapaz procurou e disse: 'Não, tu estás habilitada'. E eu: 'Ah, tá, então tá, muito obrigada, não precisa mais nada? Não vai vir mais psicóloga, não vai vir mais assistente social?'. Ele: 'Não, está tudo certo, está habilitada'. E eu: 'Ah, então tá, muito obrigada'. Eu desliguei o celular e as lágrimas rolaram (P1).

Sobre o tempo de espera, a Participante 1 considerou que seu processo foi rápido. Ela falou: “. . . foram três meses que, em função de outras pessoas, foi muito rápido nesse sentido. . . Que, às vezes, o processo é muito mais demorado nesse sentido" (P1).

A frustração foi vivida pelas participantes de diferentes formas. Para a Participante 2, esse sentimento estava relacionado a sua descoberta, durante o processo, de que, mesmo habilitada em uma lista nacional (o SNA), existe uma organização em âmbito regional que determina que seu processo está atrelado principalmente ao município no qual se habilitou. Isso apareceu em sua entrevista:

Pra mim, esse processo é um pouco frustrante. A verdade é que, lá no dia que a gente foi se habilitar, o conhecimento que as moças nos passaram sobre o que seria a lista nacional. Pra mim, foi altamente frustrante, porque eu imaginei que a lista nacional era: eu concorro tanto quanto com todos os demais dentro da minha data da sentença. Mas não . . . Eu fiquei um pouco frustrada com essa coisa de ter botado que pode ser de qualquer lugar do Brasil e em verdade não vai ser (P2).

Ela fez referência ainda aos seus sentimentos relacionados à espera: “. . . Não é ansiedade que eu 
sinto. Naturalmente eu sou ansiosa por uma série de coisas, mas a ansiedade que eu sinto, ela é um misto com a frustração do processo que eu acho que é demorado" (P2). Ainda sobre o sentimento de frustração, a Participante 4 mencionou a dificuldade em conseguir realizar as entrevistas para a habilitação: “Eu peguei férias forenses e licença da psicóloga, eu fiquei muito frustrada com aquilo, porque eu queria o quanto antes que aquele processo terminasse pra já entrar na fila, né?" (P3).

O processo de habilitação à adoção foi descrito pela Participante 4 como doloroso: "Então, é dolorido, né. Dolorido para entrar, dolorido para preencher o formulário e, depois, dolorido para esperar. Acho que a espera é mais dolorida, e tu encontra muito mais pessoas que te estimulam a não adotar do que a adotar" (P4). Para ela, etapas como o preenchimento do formulário, especialmente sobre o perfil da criança desejada, foram difíceis de lidar:

Um filho biológico também pode nascer com problemas de saúde. Tudo bem, mas aí tu não tens essa opção. $O$ adotivo tu podes adotar ou não. Tu tens essa opção. .. É diferente de um formulário pro biológico, né? E o preenchimento do formulário é muito duro. . . parece que tu tá comprando uma mercadoria ou escolhendo uma mercadoria, e dá uma sensação horrível. Tu te sente uma pessoa preconceituosa, porque não é só questões de pele, tem questões de doenças tratáveis ou não tratáveis, né, das deficiências. É muito duro tu preencheres esse formulário (P4).

É importante destacar que inicialmente a Participante 4 e seu marido tiveram uma resposta negativa no processo de habilitação à adoção. Somente após recorrerem conseguiram a aprovação:

Bem dolorido, né. É que foi negado num primeiro momento porque nós, claro, nunca tínhamos entrado, vivenciado essa questão, né. . E a primeira impressão foi péssima, que realmente essa criança ficou mais longe ainda pra nós do que a gente achava. É muito cansativo, a gente repete a mesma história umas vinte vezes e não é só nossa história, é a história de todo o núcleo familiar. Existe acho que uma pressão muito grande pra ter certeza de que tu queres adotar, é a impressão que a gente tem $(\mathrm{P} 4)$.
A morosidade foi relatada pela participante 3: “A demora, né, esse processo de adoção mesmo que é ainda moroso no Brasil, nê" (P3). Essa participante precisou aguardar as férias forenses e a licença da psicóloga responsável por seu processo para que pudesse dar seguimento à habilitação à adoção:

Ninguém me ligou. Eu fui no dia marcado da entrevista, eu cheguei lá e me disseram: 'Ah, mas não, a doutora tá em licença'. Ela respondeu: 'E por que ninguém me avisou? Eu tive que sair do trabalho, eu tive que vir aqui. E, além disso, a expectativa, a frustração que eu tô tendo, de nem saber quando é que eu vou [encontrá-la]'. [Ao que lhe responderam]: 'Ah, porque, ela vai voltar e vai tirar 15 dias mais'. (P3).

Apesar desses obstáculos em seu processo, a Participante 4 se sentiu acolhida pelos técnicos judiciários: "Eu me senti acolhida quando eu fiz as entrevistas. A psicóloga foi muito legal, gostei muito. A assistente social também, foi muito bacana. Assim, elas foram bárbaras" (P3).

\section{Sentimentos na espera no SNA}

As quatro entrevistadas fizeram referência aos sentimentos próprios da espera no SNA, ou seja, a espera após a aprovação no processo de habilitação à adoção. Foi possível identificar que estes poderiam ser alocados em duas diferentes categorias: esperança e desesperança. A esperança se relacionou a relatos de tranquilidade e preenchimento do tempo de espera a fim de manter-se bem durante o processo. Por sua vez, a desesperança apareceu conectada aos sentimentos de frustração, dor e descrença quanto à chegada da criança e ao fim da espera.

As Participantes 1 e 3 demonstraram sentimentos de esperança em seus discursos por meio da sensação de tranquilidade em relação ao momento de espera no SNA:

Antes eu tava com aquela ansiedade, aquela angústia de não poder ter filho. De ter deixado pra ter tarde, não ter arriscado em fazer inseminação, enfim. E naquela dúvida, adoto ou não adoto, e aí adotei. Quer dizer, me habilitei. Então acho que eu tô mais relaxada, assim. Tô mais tranquila porque eu sei que no final vai dar tudo certo. Porque eu já tô na fila, pode e vai demo- 
rar. Quer dizer não, não pode demorar [risos]. Vai demorar, mas eu sei que vem. O meu bebê vem,é só questão de tempo né(P3).

Ainda, a mesma participante falou: "Eu tô na gestação mesmo, né, bem dizer. Só que é um pouquinho mais longa a minha gestação" (P3). Já a Participante 1 mencionou: "Eu estou muito tranquila porque quando a gente decide já tá mais ou menos tudo pensado, tudo organizado e o medo é só se eu vou ser uma boa mãe" (P1). Complementando, ela disse ainda: “Eu penso nela [filha], mas tá guardadinho" (P1).

O sentimento de ansiedade esteve presente no discurso da Participante 1:

Nos primeiros meses... eu achei que, como eu faço aniversário, eu já achei que podia ganhar de aniversário, né? Ah, doce ilusão. Mas foi nos primeiros meses assim, parecia que o telefone ia tocar a qualquer momento sendo do foro. Depois acho que foi acalmando aquela ideia e deu uma acalmada (P1).

Tanto a Participante 1 quanto a 4 dizem estar se envolvendo com outras atividades, especialmente relacionadas ao trabalho, para se distrair enquanto seus filhos não chegam, como fica claro na fala da Participante 3: "Eu tô naquela assim que vai demorar, então, eu tô me programando, tô nos meus projetos. De acordo com essa espera. Não tô naquela expectativa que vão me chamar amanhã. Tô numa transição profissional, o meu foco tá sendo isso" (P3).

Ambas as participantes (P1 e P3) referiram que os momentos de maior dificuldade eram aqueles nos quais presenciavam crianças com os pais, ou então as datas comemorativas relacionadas à família: "Caminhar no [parque] e passar pela pracinha é um sacrifício que eu faço [risos]. Porque, ah! Eu queria tá ali com o meu bebê, brincando, entendeu?" (P3); “Eu via a propagando do Dia das Mães e ficava mais sensibilizada, né?” (P1).

O sentimento de desesperança estava presente nos relatos das participantes 2 e 4 . A Participante 4 contou que recebeu a estimativa de sete a dez anos de espera para o perfil desejado de criança, o que, para ela, tornou a espera no SNA muito dolorida, sentimento com o qual ela também já havia descrito o processo de habilitação à adoção. Quando questionada sobre o que estava sendo mais difícil em seu momento de espera, essa entrevistada disse:
"[Saber] que a criança não vai chegar, que a gente não vai aguentar a espera de sete a dez anos, né, pelo fator idade nosso" (P4). A imprevisão no processo de adoção parecia gerar descrença quanto à chegada do filho para a participante. Nesse caso, os relatos eram de que ela e o parceiro acreditavam que, com o passar dos anos de espera e o envelhecimento, não conseguiriam dar conta das demandas de um bebê. Ela demonstrava dúvidas em relação à futura adoção: “. . . Na verdade, eu não sei se o bebê vem, o bebê tá muito longe pra mim ainda" (P4). A incerteza do tempo tornava significativamente desconfortável a espera para essa participante: "A gente precisa saber o que vai acontecer no futuro, que a gente não tem a bola de cristal. Preciso fazer planos além da adoção. Tem que fazer outros planos pra dar conta da não adoção, né? Pra não pirar" (P4). A Participante 4 parecia estar descrente de que se tornaria mãe por adoção durante sua espera no SNA.

No discurso também relacionado à desesperança da Participante 2 identificou-se a frustração com a espera: "Eu gostaria de acreditar que vão ligar pra nós semana que vem, mês que vem, ou daqui dois meses. Mas não, é uma espera frustrante porque quem sabe daqui um ano, daqui dois anos, não sei" (P2). Complementando a resposta, ela mencionou que pensava em tentar se habilitar em outro lugar como forma de diminuir o tempo de espera:

De alguma forma, tentar se habilitar em outro lugar, se fosse possível, que eu já sei que não é, mas eu gostaria. Porque eu sei que é mais rápido assim, e a gente parece que perde tempo de estar com uma criança que a gente quer, um filho que a gente deseja. Acho ruim essa espera. Não é legal (P2).

Essa entrevistada disse que pensava em pedir ao marido que solicitasse transferência em seu emprego para que eles pudessem transferir também o processo de adoção, o que ela acreditava que resultaria em um tempo menor de espera. Comparando a espera na adoção com a espera no processo biológico, a Participante 2 demonstrou sua frustração:

Quando tu tá grávida, biologicamente, sempre tem né: 'ah, faltam seis meses'. Tem um momento: 'Ah, agora eu sei o sexo', 'Agora tá com não sei quantos centímetros'. Essa é a parte que a notícia é sempre igual: esperando, esperando. Não existe 'agora eu sou a décima da fila, nona 
da fila, não! Cada criança tem uma fila. Então, é uma espera sem fim. Essa é a parte ruim, essa é a frustrante (P2).

A descrição de uma espera sem fim e os relatos de descrença quanto à chegada do filho adotivo conferem um caráter de desesperança ao discurso das Participantes 2 e 4 quanto à espera no SNA.

Em síntese, as participantes fizeram contribuições importantes para o entendimento das diferentes esperas. Na habilitação à adoção, a frustração foi mencionada por duas participantes (P2 e P3), a apreensão foi relatada por uma das entrevistadas (P1), a dor foi expressa por apenas uma participante (P4) e a morosidade foi descrita por uma entrevistada (P3). A respeito da espera na fila do SNA, as participantes que demonstraram sentimentos de esperança (P1 e P3) o fizeram de forma semelhante, por meio de relatos de tranquilidade e busca da ocupação do tempo de espera pelo filho adotivo com atividades especialmente relacionadas ao trabalho, que lhes proporcionavam bem-estar. Por sua vez, as entrevistadas que referiram sentimentos de desesperança (P2 e P4) indicaram frustração (P2), dor (P4) e descrença quanto à chegada do filho adotivo e o fim da espera pela adoção (P2 e P4). Nos casos das participantes que demonstraram esperança (P1 e P3) não houve relatos de desesperança.

Alguns desses sentimentos, apesar de terem sido nomeados da mesma forma nas duas etapas de espera pela adoção, tinham significados diferentes de acordo com os relatos das participantes. Uma participante que relatou dor nas duas etapas (P4) mencionou que, na habilitação à adoção, essa emoção estava conectada às decisões quanto ao perfil da criança que desejavam adotar, enquanto na espera na fila do SNA a dor fazia referência à descrença de que o filho adotivo de fato chegaria no tempo que a família se considerava apta a recebê-lo. Ainda, os relatos de duas participantes que manifestaram frustração na habilitação à adoção tinham ligação com a percepção de que a espera seria significativamente longa (P2) e com as dificuldades de marcar os encontros com os técnicos judiciários para prosseguir com o processo (P3). Quando na fila de espera do SNA, a frustração foi relatada por apenas uma participante (P2), que se queixava da falta de marcadores temporais que indicassem a proximidade da chegada da criança e dizia que sua espera parecia sem fim.

\section{Discussão}

O discurso das participantes deste estudo indicou que há diferentes mobilizações de sentimentos nessas duas etapas próprias da transição para a maternidade por adoção. Os resultados desta investigação corroboram o estudo de Schettini et al. (2006) e evidenciam a necessidade de escuta dos sentimentos relatados durante a transição para a maternidade de mulheres em espera pela adoção.

A respeito dos sentimentos referentes ao processo de habilitação à adoção, as entrevistadas indicaram apreensão, frustração, dor e morosidade em suas falas. A apreensão, também encontrada no estudo de Fontenot (2007), estava significativamente relacionada ao processo de avaliação na habilitação à adoção. Esses achados corroboram outros estudos (Brodzinsky \& Pinderhughes, 2002; Dance \& Farmer, 2014; Paiva, 2004) que sugerem que os indivíduos que vivenciam a habilitação à adoção podem entendê-la como uma avaliação, além de terem a sensação de que estão sendo julgados (Daniluk \& HurtigMitchell, 2003). A falta de aviso sobre a sentença final da habilitação à adoção também esteve relacionada à apreensão nesse processo, o que apoia os achados de Sandelowski et al. (1991), que indicam uma sensação de perda de controle devido aos problemas na verificação de informações quanto ao processo.

Ainda, a frustração nessa etapa de espera foi relatada por duas participantes, sentimento frequentemente relatado nos estudos sobre a espera na adoção (Dance \& Farmer, 2014; Daniluk \& HurtigMitchell, 2003; Geen et al., 2004). Para uma das entrevistadas, havia um desapontamento quanto aos trâmites do processo de adoção. A burocracia na habilitação à adoção é relatada por Costa e Kemmelmeier (2013) como responsável por turbulências psíquicas e desmotivação com o processo. Já para outra participante, a frustração estava relacionada às dificuldades em seu processo quanto ao agendamento dos encontros com os técnicos judiciários, o que também foi descrito no estudo de Dance e Farmer (2014).

O sentimento de dor durante a habilitação à adoção foi expressivo no relato de uma das participantes. Essa sensação se destacou durante o preenchimento dos formulários, em especial quanto às decisões sobre o perfil da criança desejada. Esse resultado corrobora outros achados da literatura (Daniluk \& HurtigMitchell, 2003; Santos, 1987), que indicam que os pais podem se sentir desconfortáveis, durante habilitação 
à adoção, com as decisões em relação ao perfil da criança que desejam adotar. Este estudo legitima o que esses estudiosos apontaram também a respeito da necessidade de pais por adoção precisarem atingir um nível mais elevado de certeza em sua decisão de ter um filho, em vista de todas as escolhas e providências que precisam tomar na habilitação à adoção.

É importante destacar que a participante que relatou dor em seu processo de habilitação à adoção recebeu uma resposta negativa em sua primeira sentença, da qual ela recorreu, tendo um retorno positivo posteriormente. O estudo de Selwyn (1991) destacou que casais com problemas de infertilidade, como é o caso dessa entrevistada, podem experimentar a sensação de perda de controle e aumento do sentimento de impotência diante da experiência de rejeição no processo de habilitação. Assim, se faz importante o acompanhamento psicológico dessas famílias a fim de elaborar os lutos ligados à infertilidade (Mahl, Jaeger, Patias, \& Dias, 2012; Schettini et al., 2006) e à negação de sua única alternativa para o exercício da parentalidade.

A sensação de morosidade durante a habilitação à adoção também foi encontrada neste estudo. A lentidão nessa etapa ocorreu no caso de uma das participantes, que precisou aguardar as férias forenses e a licença da psicóloga responsável por seu processo, o que atrasou a marcação dos encontros com os técnicos judiciários. Ao buscar respostas para esse problema ela ouviu que deveria aguardar o retorno da profissional. Esse dado de dificuldade quanto à demora na habilitação à adoção é bastante presente na literatura sobre o tema (Costa \& Kemmelmeier, 2013; Dance \& Farmer, 2014; Gondim et al., 2008; Mahl \& Jaeger, 2011; Oliveira, Solto, \& Silva Jr., 2017). A indeterminação temporal do processo de habilitação à adoção causa desgaste para aqueles que lidam com essa espera (Huber \& Siqueira, 2010).

Sobre os sentimentos na espera no SNA, estes foram classificados neste estudo de acordo com duas categorias que emergiram dos resultados: esperança e desesperança. A esperança esteve relacionada à sensação de tranquilidade e ao preenchimento do tempo de espera com outras atividades de interesse da futura mãe por adoção. Por outro lado, a desesperança surgiu ligada ao sentimento de frustração e descrença sobre a chegada da criança e o fim da espera.

Duas mães relataram sentimentos de esperança em sua espera após a habilitação à adoção e se definiam como tranquilas. Uma das entrevistadas disse que, quando estava pensando sobre a inseminação artificial, experimentou uma forte sensação de ansiedade, o que passou com a decisão pela adoção e não realização do procedimento. Ela pôde sentir-se então relaxada, como descreveu. Os relatos dessa entrevistada demonstraram a sensação de sucesso após a habilitação e, ainda, a sensação de otimismo frente à adoção. Esse achado corrobora a afirmação de Sandelowski et al. (1991), que sugeriram que indivíduos inférteis podem se sentir avançando na transição para a parentalidade quando conseguem a aprovação na habilitação à adoção. Essa mesma participante fez referência ao processo de gestação de forma significativa quando falou da sua espera pela adoção. Além dela, outras duas participantes também definiam sua espera como um processo de gestação, informações que apoiam os achados da literatura (Cecílio \& Scorsolini-Comin, 2016; Huber \& Siqueira, 2010; Mahl \& Jaeger, 2011; Schettini et al., 2006).

O preenchimento do tempo de espera pela adoção como forma de manter a esperança diante do processo foi apontado por duas participantes. Atividades relacionadas especialmente ao trabalho pareciam servir como uma válvula de escape (Mahl \& Jaeger, 2011) para as entrevistadas. A organização e a regulação dos pensamentos e das atividades durante a espera para tornar-se mãe por adoção são importantes, pois auxiliam na construção do significado da espera dessas mulheres (Sandelowski et al., 1991). Para essas duas participantes, os momentos de maior dificuldade com a espera relacionavam-se aos encontros em espaços públicos com pais e filhos em interação e às datas comemorativas relacionadas à família, como o Dia das Mães. Esses achados confirmam a sugestão do estudo de Sandelowski et al. (1991), segundo a qual feriados que celebram a relação entre pais e filhos, assim como encontros casuais com pais e seus filhos, podem desencadear uma ansiedade intensa pela chegada do filho adotivo.

Entre os sentimentos descritos que foram alocados na categoria desesperança, a descrença quanto à chegada do bebê foi significativa no discurso de uma participante. Essa entrevistada já havia referenciado o processo de habilitação como doloroso e o fez também sobre sua espera no SNA. Com base em uma previsão de sete a dez anos de espera pelo filho adotivo, a participante dizia sentir que seu bebê não chegaria e que ela e o marido poderiam, devido ao avanço de suas idades, desistir antes mesmo de a criança chegar. Esse achado 
apoia a literatura que fala sobre a dificuldade dos pais em manterem-se animados com a possibilidade de chegada da criança com o passar dos anos (Daniluk \& Hurtig-Mitchell, 2003; Sandelowski et al., 1991). Essa entrevistada demonstrava sinais de construção de uma perspectiva cada vez mais negativa em relação à espera pela adoção, como sugerem Sandelowski et al. (1991).

A frustração também foi um sentimento relacionado à desesperança neste estudo. Para uma das futuras mães por adoção, a indeterminação do tempo gerava ansiedade. $\mathrm{O}$ extenso tempo de espera entre a habilitação e a colocação da criança na família tem seu efeito naqueles que aguardam pela adoção, conforme indicam Dance e Farmer (2014). Como descrito na literatura, as impressões de estar à deriva no tempo (Sandelowski et al., 1991) e/ou de estar esquecido ao longo dessa espera (Reppold et al., 2005) também estão presentes no discurso desta participante. Essa entrevistada chegou a definir a espera no SNA como "uma espera sem fim", o que se relaciona à importância da elaboração de um horizonte temporal capaz de dar significado à espera dessas mulheres (Sandelowski et al., 1991).

Por fim, é importante destacar que as expectativas das participantes estavam centradas na espera de bebês de 0 a 6 meses e de 0 a 2 anos de idade. Essa delimitação de idade, somada à escolha de crianças saudáveis e sem irmãos, representa o perfil mais visado pelos adotantes (Knopman, 2014) e, portanto, a definição que mais impacta o tempo de espera dos pretendentes. Uma das entrevistadas mencionou que poderia ficar de 7 a 10 anos - ou mais - em espera no SNA devido à decisão de adotar um bebê de $0 \mathrm{a} 2$ anos. Sabe-se que muitas ações, inclusive do âmbito jurídico, têm tentado elucidar para os adotantes quem são as crianças disponíveis para a adoção que, em sua maioria, não atendem ao perfil visado pelos pretendentes. É preciso estar ciente de que toda e qualquer restrição, ao definir o perfil da criança que será adotada, influencia diretamente o tempo de espera dos habilitados à adoção e, portanto, deve ser muito bem refletida por quem decide adotar.

Os achados deste estudo indicam a importância de compreender os sentimentos das mulheres em espera pela adoção de acordo com uma organização temporal baseada na etapa do processo de adoção que elas vivenciam. Os sentimentos, antes relatados na literatura de forma agrupada e pouco delimitada, foram identificados e demarcados de acordo com a fase de espera, o que elucidou as experiências das mulheres em duas diferentes esperas: na habilitação à adoção e no SNA. Entende-se que a habilitação à adoção e a espera na fila do SNA são momentos distintos dentro da espera pela adoção e que mobilizam sentimentos com significados diferentes. Mesmo as emoções que foram nomeadas de forma igual nessas duas etapas de espera, quando analisadas por meio do discurso das participantes, não tinham a mesma definição. Esses resultados evidenciam a importância de escutar e diferenciar os sentimentos relatados nessas duas fases da espera pela adoção.

\section{Considerações finais}

Como apontado por Sandelowski et al. (1991), a falta de marcadores temporais na transição para a parentalidade por adoção denuncia a carência de informações ao longo desse processo e a necessidade de significação do tempo para quem espera. Caracterizar essa forma de tornar-se mãe por meio das emoções relatadas, levando em conta suas diferentes etapas, fez-se necessário para a compreensão adequada do fenômeno. Este estudo contribuiu para a literatura sobre a espera na adoção ao identificar e delimitar os sentimentos próprios da espera na habilitação à adoção e da espera no SNA.

Por meio dos resultados deste estudo, é possível entender que existem sentimentos próprios de cada etapa da espera pela adoção. Nesta investigação destacaram-se os sentimentos de apreensão, frustração, dor e morosidade diante do processo de habilitação à adoção. Já na espera no SNA, os sentimentos puderam ser classificados entre duas diferentes categorias: esperança e desesperança. Apesar de sentimentos de dor e frustração do processo terem sido relatados tanto na espera na habilitação à adoção quanto na espera no SNA, estes se apresentaram de formas distintas em cada uma dessas fases. Na habilitação à adoção, a dor foi expressa por meio das dificuldades frente às decisões em relação ao perfil da criança desejada e a frustração estava relacionada à percepção de que o tempo de espera seria longo e à dificuldade de marcar os encontros com os técnicos judiciários. Na fila do SNA, o sentimento de dor referiu-se à desesperança de que o filho adotivo chegaria de fato. Por sua vez, a frustração esteve conectada à desesperança por meio de relatos de falta de marcadores temporais no processo de adoção e da sensação de uma espera sem fim. Esses achados 
evidenciam a importância da identificação da etapa de espera pela adoção e sugere que a descrição de um mesmo sentimento pode ter diferentes significados de acordo com seu contexto.

Apesar de não ser o foco deste estudo, destacam-se ainda os esforços das futuras mães por adoção entrevistadas em tentarem criar uma linha do tempo, como sugere Sandelowski et al. (1991), para simbolizar seus processos de espera. O recurso ao termo gestação parece surgir de forma espontânea para essas mulheres que buscam explicar como se sentem ao esperar pela chegada do filho adotivo. Uma gestação adotiva (Huber \& Siqueira, 2010) ou emocional (Schettini et al., 2006), como sugere a literatura, pode ser fator protetivo para a saúde mental dessas mulheres, que se encontram em uma espera sem roteiro. Compreende-se que gestar psiquicamente diz respeito ao desejo delas de se entregarem ao processo de transição para a maternidade por adoção.

As limitações desta investigação dizem respeito ao pequeno número de casos investigados. Apesar disso, entende-se que todos os possíveis casos da comarca participante do estudo foram contatados e que as pessoas que se disponibilizaram, por meio do contato nas mídias sociais, também foram incluídas nesta investigação. Ainda, acredita-se que o acompanhamento dessas mulheres durante seus anos de espera pela adoção pode resultar em um conhecimento mais profundo dos efeitos do tempo nesse processo de tornar-se mãe. Nesse sentido, novos estudos poderiam ser realizados a partir de um delineamento longitudinal.
Espera-se que este estudo possa inspirar novas pesquisas sobre a espera no processo de adoção, auxiliando no aprimoramento das pesquisas sobre a parentalidade por adoção. Sugerem-se algumas medidas simples que podem auxiliar a aliviar os sentimentos de angústia e frustração, como o estabelecimento de avisos sobre a sentença final e encerramento do processo de habilitação. Ainda, a previsão e a precisão no agendamento dos encontros entre as famílias e os técnicos judiciários responsáveis podem significar a promoção de bem-estar para as mulheres em espera pela adoção.

Por fim, os resultados desta pesquisa reforçam o comprometimento, a força e a capacidade de resiliência, já destacados na literatura (Solchany, 1998), dessas mulheres que esperam pela adoção. Manter as expectativas e, especialmente, as esperanças durante as diferentes esperas, repletas de sentimentos intensos, parece ser uma tarefa complexa. Reconhece-se que o aprimoramento dos estudos sobre o aspecto emocional das famílias em espera pela adoção é fundamental para a compreensão da constituição psicológica das famílias adotivas. Estar esperando - tanto na habilitação à adoção quanto na fila do SNA - diz respeito à transição para a parentalidade na adoção e, por isso, merece atenção dos estudiosos sobre o tema. Além disso, destaca-se a importância de espaços de acolhida dos sentimentos advindos da espera para que os futuros pais por adoção possam, dessa forma, exprimir suas opiniões e realizar trocas de experiências sobre o tema.

\section{Referências}

Braun, V., \& Clarke, V. (2006). Using thematic analysis in psychology. Qualitative Research in Psychology, 3(2), 77-101. https://doi.org/10.1191/1478088706qp063oa

Brodzinsky, D. M., \& Pinderhughes, E. (2002). Parenting and child development in adoptive families. In M. H. Bornstein (Ed.), Handbook of parenting (pp. 279-311). Lawrence Erlbaum Associates.

Cecílio, M. S., \& Scorsolini-Comin, F. (2016). Parentalidades adotiva e biológica e suas repercussões nas dinâmicas conjugais. Psicologia: Ciência e Profissão, 36(1), 171-182. http://doi.org/10.1590/1982-3703003832015

Conselho Nacional de Justiça. (2019). SNA - Sistema Nacional de Adoção de Acolhimento. https://bit.ly/3qVebIU

Costa, L. T. M., \& Kemmelmeier, V. S. (2013). O olhar de futuros pais sobre o processo de adoção. Psicologia Argumento, 31(72), 187-196. http://dx.doi.org/10.7213/psicol.argum.7619

Dance, C., \& Farmer, E. (2014). Changing lives and changing minds: The experiences of adoptive parents from application to approval. Adoption \& Fostering, 38(2), 101-114. https://doi.org/10.1177/0308575914532057

Daniluk, J. C., \& Hurtig-Mitchell, J. (2003). Themes of hope and healing: Infertile couples' experiences of adoption. Journal of Counseling \& Development, 81(4), 389-399. https://doi.org/10.1002/j.1556-6678.2003.tb00265.x

Flick, U. (2009). Introdução à pesquisa qualitativa (3a ed.). Artmed. 
Fontenot, H. B. (2007). Transition and adaptation to adoptive motherhood. Journal of Obstetric, Gynecologic, \& Neonatal Nursing, 36(2), 175-182. https:// doi.org/10.1111/j.1552-6909.2007.00134.x

Frizzo, G. B., Silva, P. S., Resmini, G. F., Schwochow, M. S., Leão, L. C. S., Levandowski, D. C., ... Chaves, V. P. (2016). Transição para a parentalidade adotiva: Pesquisa e intervenção.

Geen, R., Malm, K., \& Katz, J. (2004). A study to inform the recruitment and retention of general applicant adoptive parents. Adoption Quarterly, 7(4), 1-28. https://doi.org/10.1300/J145v07n04_01

Gondim, A. K., Crispim, C. S., Fernandes, F. H. T., Rosendo, J. C., Brito, T. M. C., Oliveira, U. B., \& Nakano, T. C. (2008). Motivação dos pais para a prática da adoção. Boletim de Psicologia, 58(129), 161-170.

Huber, M. Z., \& Siqueira, A. C. (2010). Pais por adoção: A adoção na perspectiva dos casais em fila de espera. Psicologia: Teoria e Prática, 12(2), 200-216.

Knopman, E. B. (2014). Busca ativa na adoção. In C. Ladvocat, \& S. Diuana (Eds.), Guia de adoção: No jurídico, no social, no psicológico e na família (pp. 231-240). Roca.

Krahl, S. (2003). Expectativas e sentimentos de mulheres que aguardam pela adoção [Dissertação de mestrado]. Universidade Federal do Rio Grande do Sul.

Lei n. 12.010. (2009, 2 de agosto). Dispõe sobre adoção; altera as Leis n. 8.069, de 13 de julho de 1990 - Estatuto da Criança e do Adolescente, 8.560, de 29 de dezembro de 1992; revoga dispositivos da Lei n. 10.406, de 10 de janeiro de 2002 - Código Civil, e da Consolidação das Leis do Trabalho - CLT, aprovada pelo Decreto-Lei n. 5.452, de $1^{\circ}$ de maio de 1943; e dá outras providências. Diário Oficial da União.

Mahl, F. D., \& Jaeger, F. P. (2011). “Gestar sem gerar”: Consequências da indeterminação do tempo na espera pelo filho adotivo [Artigo apresentado]. 15º Simpósio de Ensino, Pesquisa e Extensão, São Leopoldo, RS, Brasil.

Mahl, F. D., Jaeger, F. P., Patias, N. D., \& Dias, A. C. G. (2012). Enquanto a maternidade não vem: A infertilidade e a pressão social como pano de fundo para a adoção. Pensando Famílias, 16(2), 85-102.

Núcleo de Pesquisa e Intervenção em Família com Bebês e Crianças (2016). Questionário sobre a adoção.

Núcleo de Pesquisa e Intervenção em Família com Bebês e Crianças (2016). Entrevista sobre as expectativas e os sentimentos na adoção.

Oliveira, P. A. B. A., Souto, J. B., \& Silva Jr., E. G. (2017). Adoção e psicanálise: A escuta do desejo de filiação. Psicologia: Ciência e Profissão, 37(4), 909-922. http://doi.org/10.1590/1982-3703003672016

Paiva, L. D. (2004). Adoção: Significados e possibilidades. Casa do Psicólogo.

Patton, M. Q. (2002). Qualitative research and evaluation methods (3a ed.). Sage.

Rampage, C., Eovaldi, M., Ma, C., Foy, C. W., Samuels, G. M., \& Bloom, L. (2016). Famílias adotivas. In F. Walsh (Ed.), Processos normativos da família: Diversidade e complexidade (pp. 222-248). Artmed.

Reppold, C. T., Chaves, V. C., Nabinger, S., \& Hutz, C. S. (2005). Aspectos práticos e teóricos da avaliação psicossocial para habilitação à adoção. In C. S. Hutz (Org.), Violência e risco na infância e adolescência: Pesquisa e intervenção (pp. 43-70). Casa do Psicólogo.

Sandelowski, M., Harris, B. G., \& Holditch-Davis, D. (1991). “The clock has been ticking, the calendar pages turning, and we are still waiting": Infertile couples' encounter with time in the adoption waiting period. Qualitative Sociology, 14(2), 147-173. https://doi.org/10.1007/BF00992192

Santos, N. P. F. (1987). As possibilidades de satisfação na adoção [Dissertação de mestrado]. Fundação Getúlio Vargas.

Schettini Filho, L. (1998). Compreendendo os pais adotivos. Bagaço.

Schettini, S. S. M., Amazonas, M. C. L. A., \& Dias, C. M. S. B. (2006). Famílias adotivas: Identidade e diferença. Psicologia em Estudo, 11(2), 285-293. http://doi.org/10.1590/S1413-73722006000200007

Sebastiany, N. (2011). Adoção internacional e serviço social [Trabalho de Conclusão de Curso, Universidade Regional do Noroeste do Estado do Rio Grande do Sul]. Biblioteca Digital Unijuí. https://bibliodigital.unijui.edu.br:8443/ xmlui/bitstream/handle/123456789/1073/Natalia\%20Sebastiany.pdf?sequence=1\&isAllowed=y

Selwyn, J. (1991). Applying to adopt: The experience of rejection. Adoption \& Fostering, 15(3), 26-29. https://doi.org/ $10.1177 / 030857599101500307$ 
Silva, P. S. (2015). Os processos de habilitação para adoção segundo técnicos judiciários do Rio Grande do Sul [Dissertação de mestrado, Universidade Federal do Rio Grande do Sul]. Repositório Digital da UFRGS. https://lume.ufrgs.br/handle/10183/156749

Solchany, J. A. (1998). Anticipating the adopted child: Women's preadoptive experiences. The Canadian Journal of Nursing Research, 30(3), 123-129.

Souza, H. P., \& Casanova, R. P. S. (2012). Adoção: O amor faz o mundo girar mais rápido. Juruá.

Stake, R. E. (1994). Case studies. In N. K. Denzin, \& Y. S. Lincoln (Eds.). Handbook of qualitative research (pp. 236-247). Sage.

\section{Monique Souza Schwochow}

Mestre em Psicologia pela Universidade Federal do Rio Grande do Sul (UFRGS), Porto Alegre - RS. Brasil.

E-mail: moniqueschwochow@gmail.com

(1) https:// orcid.org/0000-0002-4424-5005

\section{Giana Bitencourt Frizzo}

Doutora em Psicologia pela Universidade Federal do Rio Grande do Sul (UFRGS), Porto Alegre - RS. Brasil.

E-mail: gifrizzo@gmail.com

(D) https://orcid.org/0000-0001-8106-4441

Agradecemos ao Conselho Nacional de Desenvolvimento Científico e Tecnológico (CNPq) pelo auxílio financeiro recebido por meio do edital Universal concedido ao projeto "Transição para a parentalidade adotiva: pesquisa e intervenção".

Endereço para envio de correspondência:

Rua Ramiro Barcelos, 2600, sala 112, Santa Cecília. CEP: 90035-003. Porto Alegre - RS. Brasil.

Recebido 28/05/2018

Aceito 06/11/2019

Received 05/28/2018

Approved 11/06/2019

Recibido 28/05/2018

Aceptado 06/11/2019

Como citar: Schwochow, M. S., \& Frizzo, G. B. (2021). Mulheres em espera pela adoção: Sentimentos apresentados nas diferentes etapas desse processo. Psicologia: Ciência e Profissão, 41 (n.spe 3), 1-15. https://doi.org/

$10.1590 / 1982-3703003201165$

How to cite: Schwochow, M. S., \& Frizzo, G. B. (2021). Women waiting to adopt a child: Feelings experienced in the different stages of the process. Psicologia: Ciência e Profissão, 41 (n.spe 3), 1-15. https://doi.org/10.1590/19823703003201165

Cómo citar: Schwochow, M. S., \& Frizzo, G. B. (2021). Mujeres en espera por la adopción: Sentimientos en las diferentes etapas del proceso. Psicologia: Ciência e Profissão, 41 (n.spe 3), 1-15. https://doi.org/10.1590/19823703003201165 